\title{
Sosialisasi Ekonomi Syariah Bagi Generasi Milenial (Studi Kasus Pada Siswa Dayah Terpadu Al-Muslimun)
}

\author{
Angga Syahputra ${ }^{*}$, M. Syafril Nasution ${ }^{2}$, Ramadhan Razali ${ }^{3}$, Trie Nadilla ${ }^{4}$ \\ IAIN Lhokseumawe \\ 1e-mail: a.syahputra3791@ gmail.com \\ ${ }^{2}$ e-mail: muhamadsyafrilnst@iainlhokseumawe.ac.id \\ 3e-mail: ramadhan@iainlhokseumawe.ac.id \\ ${ }^{4}$ e-mail: trienadilla@iainlhokseumawe.ac.id \\ *Corresponding Author
}

\begin{abstract}
ABSTRAK
Pengabdian pada masyarakat ini bertujuan untuk memberikan sosialisasi ekonomi syariah bagi siswa tingkat aliyah di Dayah Terpadu Al-Muslimun, Lhoksukon Kabupaten Aceh Utara. Sosialisasi merupakan salah satu metode yang digunakan untuk meningkatkan literasi ekonomi syariah di masyarakat. Dari berbagai penelitian diketahui Muslim milenial berperan penting dalam perkembangan ekonomi syariah, untuk itu penting dilakukan sosialisasi guna meningkatkan literasi di kalangan Muslim milenial. Indonesia sendiri saat ini tengah gencar mengembangkan ekonomi syariah dengan berbagai gerakan yang dilakukan pemerintah, termasuk dengan dilakukannya merger Bank Mandiri Syariah, Bank BRI Syariah Tbk dan Bank BNI Syariah menjadi Bank Syariah Indonesia (BSI). Metode yang dilakukan dalam pengabdian ini dengan melakukan sosialisasi secara face to face kepada siswa Dayah Terpadu Al-Muslimun. Tim dari Fakultas Ekonomi dan Bisnis Islam - IAIN Lhokseumawe sukses melakukan sosialisasi ekonomi syariah kepada siswa aliyah Dayah Terpadu Al-Muslimun. Siswa tampak antusias selama sosialisasi berlangsung bahkan berkomitmen ingin menjadi bagian langsung dalam pengembangan ekonomi syariah Indonesia ke depannya.
\end{abstract}

Kata Kunci: Sosialisasi; Generasi Milenial; Dayah Terpadu Al-Muslimun

\begin{abstract}
This community service aims to provide socialization of sharia economy for aliyah students at the Al-Muslimun Integrated Dayah, Lhoksukon, North Aceh Regency. Socialization is one of the methods used to increase Islamic economic literacy in society. From various studies it is known that millennial Muslims play an important role in the development of the sharia economy, for this reason it is important to conduct socialization to increase literacy among millennial Muslims. Indonesia itself is currently intensively developing the sharia economy with various movements carried out by the government, including the merger of Bank Mandiri Syariah, Bank BRI Syariah Tbk and Bank BNI Syariah to become Bank Syariah Indonesia (BSI). The method used in this service is by doing face to face socialization to Al-Muslimun Integrated Dayah students. Team from Faculty of Islamic Economics and Business has successful conveyed the socialization of sharia economics to Al-Muslimun's Aliyah Integrated Dayah students. The students seemed enthusiastic during the socialization and even committed to be a direct part of the development of Indonesia's sharia economy in the future.
\end{abstract}

Keywords: Socialization; Millennial Generation; Integrated Dayah Al-Muslimun 


\section{PENDAHULUAN}

Generasi milenial merupakan harapan bagi bangsa ini ke depannya. Kelak diharapkan anak-anak bangsa mampu menjadi pemimpin seperti yang diharapkan. Begitu juga dengan perkembangan ekonomi syariah, harapannya kelak anak-anak bangsa mampu menjadi roda penggerak kejayaan ekonomi syariah di Indonesia.

Potensi pertumbuhan ekonomi syariah di Indonesia masih sangat besar, karena itu diperlukan berkomitmen untuk terus melakukan sosialisasi terutama ke generasi milenial yang terus berkembang. Dengan melakukan inisiasi terhadap generasi millenial maka diharapkan mereka nantinya anak-anak milenial akan mendominasi dalam perekonomian (Laucereno, 2018).

Milenial memang diharapkan menjadi kunci dari pengembangan ekonomi syariah Indonesia. Untuk itu perlu dibangun kesadaran yang masif milenial akan ekonomi syariah agar negeri ini tidak hanya menjadi pasar saja tapi juga sebagai pelaku. Melalui sosialisasi diharapkan mainstreaming ekonomi syariah lebih banyak melibatkan generasi muda.

Saat ini potensi milenial di Indonesia mencapai 140 juta orang yang mewakili 62,98 persen penduduk di Indonesia. Porsi milenial mencapai 33,75 persen dan 29,23 persen adalah generasi sentenial atau generasi Z. Selain itu 87 persen penduduk Indonesia adalah Muslim yang menempati 12,5 persen populasi Muslim dunia. Global Islamic Economy Report 2018-2019 oleh Thomson Reuters juga menyebutkan ekonomi Islam tumbuh stabil karena didorong populasi milenial Muslim yang terus meningkat dan diperkirakan akan mencapai tiga miliar jiwa pada 2060. Belum lagi mergernya bank syariah BUMN dan juga inisiatif lain tentu akan membesarkan potensi penetrasi pada milenial. Nilai-nilai yang dibawa oleh bank syariah pun relevan dengan perkembangan tren minat dari milenial. Seperti lebih memperhatikan sisi sosial dan keberlanjutan dalam keuangan juga transaksi (Republika, 2020).

Dayah Terpadu Al-Muslimun merupakan sekolah formal dalam bentuk pesantren terpadu yang terletak di Kabupaten Lhoksukon, Aceh Utara. Di dayah ini terdapat 1.500 siswa mulai dari tingkat ibtidaiyah hingga aliyah. Dari jumlah tersebut ada sekitar 20\% jumlah siswa aliyah yang saat ini akan menentukan jurusan dalam jenjang kuliahnya (Rahmatillah, 2021), untuk itu tim dari Fakultas Ekonomi dan Bisnis Islam - IAIN Lhokseumawe hadir dalam rangka memberikan sosialisasi, perkembangan dan penyuluhan pentingnya ekonomi syariah kepada siswa di tingkat aliyah agar dapat menjadi bagian dari bagian dari ekonomi syariah.

\section{BAHAN DAN METODE}

Dalam rangka memberikan sosialisasi kepada siswa tingkat akhir Madrasah Aliyah Dayah Terpadu Al-Muslimun, tim dari Fakultas Ekonomi dan Bisnis Islam - IAIN Lhokseumawe 
mengagendakan untuk datang langsung mengunjungi siswa di Kabupaten Lhoksukon, Aceh Utara pada 16 Februari 2021.

Kegiatan sosialisasi ini direncanakan berlangsung seharian kepada siswa tingkat akhir aliyah. Adapun metode yang digunakan adalah menggunakan tatap muka langsung dengan tetap memperhatikan protokol kesehatan. Kegiatan ini rencananya akan berlangsung di Aula Dayah Terpadu Al-Muslimun ini diisi dengan empat orang narasumber dari Fakultas Ekonomi dan Bisnis Islam - IAIN Lhokseumawe. Adapun nantinya materi sosialisasi yang akan disampaikan kepada siswa adalah seputar ekonomi syariah, perkembangannya, peluang serta tantangan yang ada.

Sebelum sosialisasi ini dilaksanakan, tim terlebih dahulu meninjau lokasi, berkirim surat dan melakukan silaturahmi kepada pengurus Dayah Terpadu Al-Muslimun, guna memaparkan maksud dan tujuan diadakannya sosialisasi. Pengurus Dayah Terpadu Al-Muslimun tampak menyambut hangat rencana ini serta mendukung kegiatan ini dengan memberikan fasilitas tempat dan hal-hal yang diperlukan tim dalam rangka sosialisasi ekonomi syariah.

\section{HASIL DAN PEMBAHASAN}

Ekonomi syariah adalah sebuah pangsa besar yang mencakup berbagai industri. Di Indonesia saat ini mulai muncul kesadaran masyarakat Muslim untuk ber-Islam secara kaffah yang kemudian muncul istilah halal lifestyle. Hal ini dibuktikan dengan semakin ramainya kegiatan Muslim, mulai dari produk makanan maupun minuman halal, kajian yang bertebaran di berbagai tempat tidak hanya masjid, fashion Muslim yang semakin diminati sehingga banyak Muslimah yang menggenakan hijab serta keuangan syariah yang diminati bagi kaum Muslim untuk menghindari unsur riba yang sangat dilarang dalam ajaran Islam. Di bidang keuangan syariah tentu menciptakan prinsip filantropi selain mengejar keuntungan material. Filantropi ini berguna sebagai distribusi kekayaan salah satunya adalah wakaf. Wakaf merupakan sarana penyediaan fasilitas yang dapat dimanfaatkan secara publik (Masyarakat Ekonomi Syariah, 2019). Belum lagi saat ini pariwisata halal juga menjadi destinasi baru dan peluang ekonomi yang sangat besar jika dikelola dengan baik, tentunya dengan SDM yang mumpuni.

Istilah generasi milenial memang saat ini sedang akrab didengar. Istilah tersebut berasal dari millennials yang diciptakan oleh dua pakar sejarah dan penulis Amerika, William Strauss dan Neil Howe dalam beberapa bukunya. Millennial generation atau generasi Y juga akrab disebut generation me atau echo boomers. Secara harfiah memang tidak ada demografi khusus dalam menentukan kelompok generasi yang satu ini. Namun, para pakar menggolongkannya berdasarkan tahun awal dan akhir. Penggolongan generasi Y terbentuk bagi mereka yang lahir pada 1980 1990, atau pada awal 2000, dan seterusnya (Hutagalung, Fitri, \& Ritonga, 2019). 
Teori lain tentang generasi milienial dikemukakan oleh Elwood Carlson dalam bukunya berjudul The Lucky Few: Between the Greatest Generation and the Baby Boom. Menurutnya, generasi milenial adalah mereka yang lahir dalam rentang tahun 1983 sampai dengan 2001. Jika didasarkan pada Generation Theory yang dicetuskan oleh Karl Mannheim pada tahun 1923, maka generasi milenial adalah generasi yang lahir pada rasio tahun 1980 sampai dengan 2000. Generasi milenial juga disebut sebagai generasi Y. Istilah ini mulai dikenal dan dipakai pada editorial koran besar Amerika Serikat pada Agustus 1993 (Tim Kementerian Pemberdayaan Perempuan dan Perlindungan Anak Dengan Pusat Statistik, 2018).

Indonesia sendiri diprediksi akan mengalami apa yang disebut dengan bonus demografi di sekitar tahun 2020-2030. Hal ini berdasarkan prediksi Badan Kependudukan dan Keluarga Berencana Nasional (BKKBN), dimana pada tahun-tahun tersebut $70 \%$ warga Indonesia berada di usia produktif, yakni antara usia 15 hingga 64 tahun. Hanya sekitar 30\% yang berusia tidak produktif, yakni mulai usia 14 tahun ke bawah dan 65 tahun ke atas.

Jika mengacu pada data BPS tahun 2019, jumlah penduduk Indonesia tahun 2020 diproyeksikan mencapai 270 juta jiwa. Dari jumlah tersebut penduduk Muslim berjumlah 229,62 juta jiwa. Dari jumlah tersebut sebanyak 66,07 juta jiwa usia 0-14 tahun dan usia 15-64 tahun berjumlah 185,34 juta jiwa. Pada tahun 2020 diperkirakan usia produktif 15-64 tahun sebesar $68,75 \%$. Hal ini merupakan bagian dari kelompok potensial, dimana anak-anak muda (kaum milenial) memiliki peran dan kontribusi yang determinan (Badan Pusat Statistik, 2020). Oleh karena itu gerakan ekonomi Islam di Indonesia harus dapat merangkul Muslim milenial.

Untuk konteks Indonesia, gaya hidup anak muda milenial akan memiliki pengaruh yang besar terhadap berbagai aspek kehidupan, baik secara personal maupun publik, baik dari sisi sosial, budaya, hingga ekonomi, politik bahkan hingga agama. Melihat uraian tersebut, anak muda Muslim memiliki posisi yang strategis. Posisi strategis itu tidak hanya untuk konteks nasional, tetapi juga internasional. Muslim milenial dapat mengangkat citra Islam Indonesia agar menjadi rujukan dunia dalam mewujudkan masyarakat yang damai dan berkeadaban (Iswanto, 2018). 


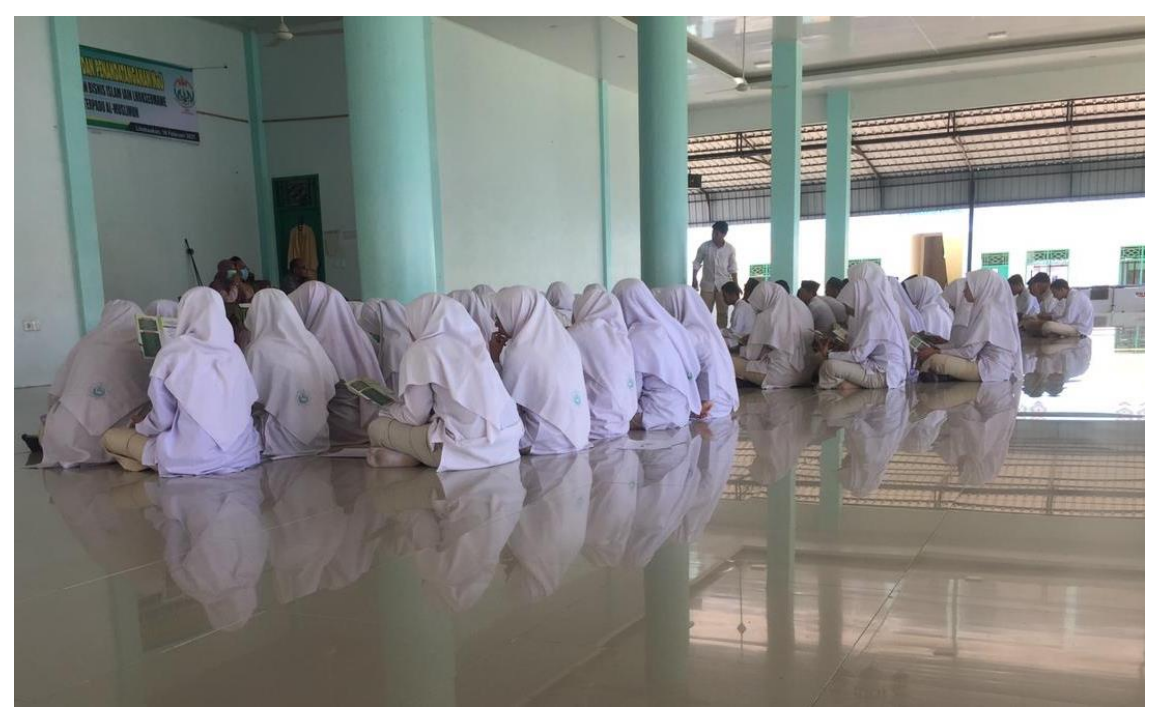

Sumber: Dokumentasi Pribadi Tim Sosialisasi

\section{Gambar 1. Suasana Saat Sosialisasi Ekonomi Syariah}

Saat pelaksanaan kegiatan sosialisasi, tampak murid tingkat akhir aliyah Dayah Terpadu Al-Muslimun begitu sangat antusias. Siswa pun tidak segan berinteraksi dengan tim dari Fakultas Ekonomi dan Bisnis Islam - IAIN Lhokseumawe. Bahkan siswa mampu berinteraksi dengan menggunakan bahasa Inggris dan bahasa Arab. Semangat energik kaum milenial begitu tampak pada wajah-wajah siswa.

Gerakan ekonomi Islam di Indonesia yang saat ini sudah berjalan 30 tahun tampaknya belum menemukan hasil yang signifikan jika dibandingkan dengan rasio jumlah Muslim Indonesia dan lembaga keuangan syariah. Umat Islam masih belum memiliki pengetahuan dan kesadaran pentingnya ekonomi Islam. Peran dan kontribusi umat Islam masih kecil dalam gerakan ekonomi Indonesia. Untuk itu sosialisasi ini sangat bermanfaat bagi generasi penerus bangsa. Sebab banyak diantara siswa yang hadir tertarik dengan perkembangan ekonomi syariah dan berminat bergabung dalam membesarkannya, namun banyak hal pula yang belum dipahami oleh siswa tentang ekonomi syariah.

Dalam hukum positif yang aplikatif, ekonomi Islam dikategorikan sebagai sistem ekonomi yang sejalan dengan ekonomi Pancasila dan bersifat compatible walaupun tidak sepenuhnya substitutable. Untuk itu, ekonomi Islam tidak boleh direduksi hanya dengan memusatkan pada upaya membangun lembaga keuangan syariah. Akan tetapi ekonomi Islam harus dapat menangkal sistem ekonomi yang eksploitatif secara luas, yang memelihara dan menumbuhkan kesenjangan ekonomi yang membiarkan terjadinya trade off secara sistematik, yang subordinatif dan diskriminatif yang membiarkan perkembangan faham dan perilaku laisse z faire (Amalia, Keadilan Distributif dalam Ekonomi Islam: Penguatan Peran LKM dan UKM di Indoensia, 2008). 
Tim sosialisasi dari Fakultas Ekonomi dan Bisnis Islam - IAIN Lhokseumawe juga turut memaparkan salah satu masalah yang dihadapi perbankan syariah saat ini yaitu persoalan Sumber Daya Manusia (SDM). Persoalan ini dipaparkan karena minat Muslim milenial untuk bekerja di dunia perbankan masih sangat tinggi. Jumlah SDM perbankan syariah sejak tahun 2011 sampai 2015 mengalami peningkatan. SDM perbankan syariah pada tahun 2015 berjumlah 61.429 orang. Dari jumlah tersebut hanya 10\% SDM perbankan syariah yang memiliki latar belakang ekonomi syariah, dan $90 \%$ berlatar belakang pendidikan ekonomi konvensional atau lulusan perguruan tinggi umum. Jumlah ini di satu sisi merupakan peluang bagi Muslim milenial yang berlatar belakang pendidikan ekonomi syariah, namun di sisi lain ini merupakan tantagan tersendiri. Secara kuantitas industri perbankan syariah saat ini mengalami kekurangan SDM yang sesuai dengan tuntutan dan kebutuhan. Namun, secara kualitas menyiapkan SDM yang profesional bukanlah sebuah persoalan yang mudah (Amalia, 2010).

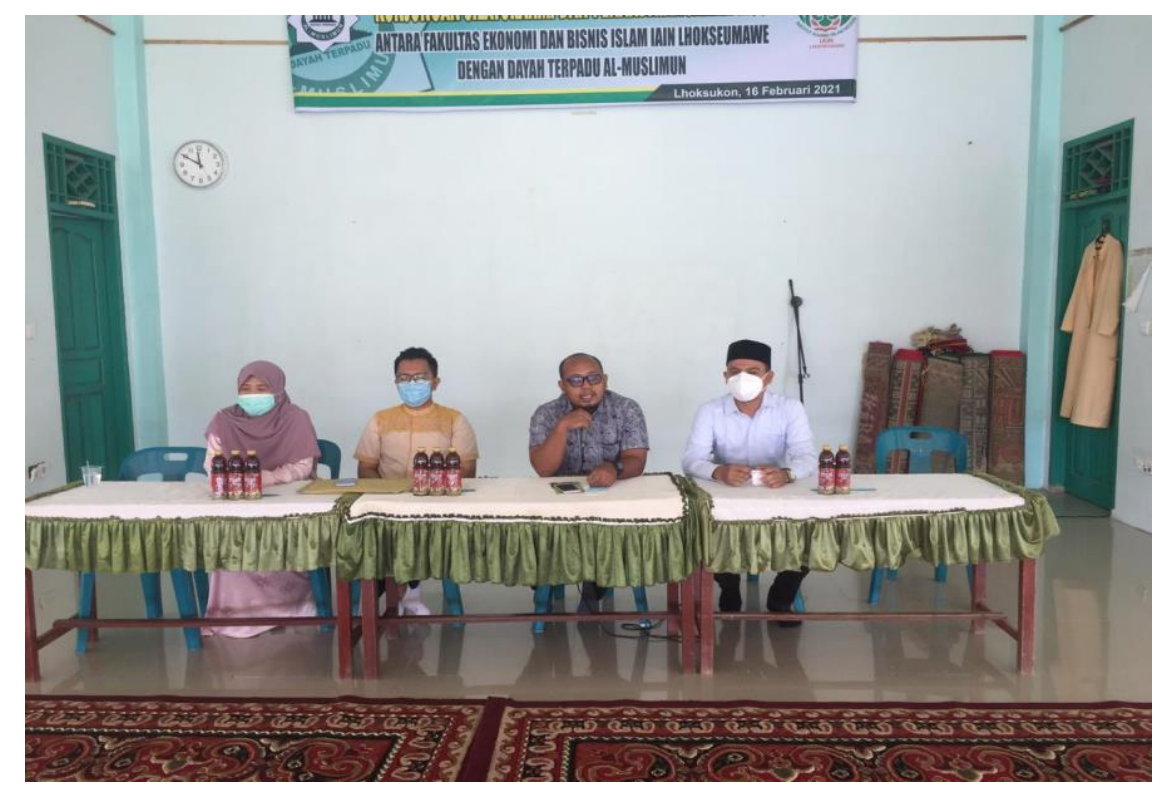

Sumber: Dokumentasi Pribadi Tim Sosialisasi

\section{Gambar 2. Tim Sosialisasi FEBI - IAIN Lhokseumawe}

Jika dihubungkan dengan perkembangan dua dasawarsa terakhir, dengan munculnya lembaga keuangan syariah antara lain bank syariah, BMT, BPRS, Takaful, dan lembaga filantropi, tidak diragukan lagi, lembaga-lembaga ini muncul dan berkembang berkat dukungan kekuatan ekonomi, sosial dan kultural kelas menengah Muslim baru, yang terus mengalami peningkatan semangat dan antusiasme keagamaan. Ini adalah ceruk pasar potensial bagi lembaga keuangan syariah di Indonesia yang harus dioptimalkan. 
Salah satu ciri Muslim milenial yaitu sadar akan pentingnya penguasaan teknologi (melek teknologi). Berdasarkan survei yang dilakukan oleh Asosiasi Penyelenggara Jasa Internet Indonesia (APJII) pada 2018 yaitu 171,18 juta jiwa (64,8\% dari total penduduk) adalah pengguna internet. Maka jika dilihat dari segi umur, pengguna internet dikuasai oleh generasi milenial (generasi yang lahir dari tahun 1980-2000).

Gerakan ekonomi Islam di Indonesia menurut teori mobilisasi sumber daya (resource mobilization theory) menekankan pentingnya diperlukan tindakan kolektif yang terorganisasi. Dalam konteks ini muslim milenial Indonesia merupakan kelompok yang terorganisasi dalam gerakan ekonomi Islam, mereka terpragmentasi dalam kelompok-kelompok seperti hijrah dan hijaber. Maka dibutuhkan pendekatan kepada kelompok tersebut (Nurhidayat, 2020)

Dari survei yang dilakukan di Amerika Serikat dan Inggris, beberapa ciri dari generasi milenial, atau yang sinonim dengannya, adalah sebagai berikut: memiliki tingkat pendidikan tinggi, mudah mengerti teknologi, berorientasi pada kepentingan umum (civic oriented - maslahat umat), warga negara yang memiliki cita-cita besar, mayoritas suka atau pelaku enterpreneur, berperilaku pragmatis-idealis, liberal, pengasih atau peduli kepada orang lain, memiliki ciri berkemajuan (progressive), percaya diri, berorientasi pada hasil, dapat mengerjakan berbagai macam tugas (multi-tasker), pengembara (nomadic), tidak sabar alias cepat marah, suka berpetualang dan berani mengambil resiko (adventurous) (Hakim, 2017).

Indonesia saat ini tengah menapaki babak penting dalam industri perbankan syariah. Hal tersebut ditandai dengan mergernya Bank Syariah Mandiri, Bank BRI Syariah Tbk, dan Bank BNI Syariah menjadi Bank Syariah Indonesia (BSI) Tbk. Kelahiran BSI ini diresmikan oleh Presiden Joko Widodo, pada 1 Februari 2021.Perbankan syariah merupakan salah satu penopang utama ekonomi dan keuangan syariah di negara ini. Saat ini, 89,26\% aset lembaga keuangan syariah merupakan kontribusi perbankan syariah. Adapun sekitar 70\% kegiatan ekonomi syariah masih bertumpu di perbankan syariah. Perbankan syariah merupakan salah satu penopang utama ekonomi dan keuangan syariah di negara ini. Saat ini, 89,26\% aset lembaga keuangan syariah merupakan kontribusi perbankan syariah. Adapun sekitar 70\% kegiatan ekonomi syariah masih bertumpu di perbankan syariah (Sayekti, 2021).

Saat ini ekonomi syariah terus berkembang pesat, termasuk yang berkaitan dengan industri halal dan dana sosial Islam yang dikenal dengan Ziswaf (zakat, infak, sedekah dan wakaf). Perkembangan industri halal yang sangat pesat ini seiring dengan bertambahnya kesadaran masyarakat akan pentingnya mengkonsumsi produk halal. Industri halal sendiri bukan hanya terkait dengan sektor makanan dan minuman, tetapi juga sektor keuangan, pariwisata, kosmetika, obat-obatan, fashion hingga media dan rekreasi halal. Dari sektor keuangan saja, pada tahun 2018 
total aset perbankan syariah telah mencapai Rp. 444 triliun atau meningkat sebesar 14.6 persen. Selain itu, total aset industri keuangan non-bank (IKNB) dan pasar modal syariah pun mengalami peningkatan yang cukup baik, dengan masing-masing total aset mencapai Rp. 98 triliun dan Rp. 662 triliun di tahun 2018 (Nursyamsiah, 2019).

Salah satu tugas besar pemerintah, akademisi dan praktisi saat ini adalah meningkatkan literasi keuangan syariah di masyarakat dan Muslim milenial. Diketahui saat ini tingkat literasi keuangan syariah di Indonesia masih sangat rendah apalagi di generasi milenial meskipun penduduk Muslim di tanah air jumlahnya sangat besar. Berdasarkan data dari Bank Indonesia (BI), tingkat literasi keuangan syariah di Indonesia baru mencapai 16.3\% (Media Indonesia, 2020), sangat jauh berbeda apabila dibandingkan dengan negara tetangga seperti Malaysia.

Faktanya saat ini Indonesia tidak hanya pangsa besar bagi industri ekonomi syariah, namun dengan bonus demografi yang ada, Muslim milenial Indonesia saat ini turut menjadi pasar pengembangan ekonomi syariah (Antara, 2021). Hanya saat ini diperlukan penataan, membuat lebih sistematis, dan membangun sinergi antar berbagai pihak.

Ekonomi syariah saat ini juga membutuhkan perjuangan dan keberpihakan kepada umat agar mendapatkan dukungan yang semakin konkret di hari-hari mendatang. Apalagi tujuan kesuksesan yang hakiki dalam berekonomi adalah tercapainya kesejahteraan yang mencakup kebahagiaan (spiritual) dan kemakmuran (material) pada tingkatan individu dan masyarakat. Untuk itu dukungan generasi milenial sangat penting dalam menggerakan ekonomi berbasis keumatan. Potensi ini adalah sebuah kekuatan besar yang harus diaktivasi dengan baik (Rosyid, 2021). Untuk itu, tim sosialisasi dari Fakultas Ekonomi dan Bisnis Islam - IAIN Lhokseumawe sejauh ini turut serta membantu dalam rangka meningkatkan literasi di kalangan generasi Muslim milenial.

\section{KESIMPULAN DAN SARAN}

Tim sosialisasi dari Fakultas Ekonomi dan Bisnis Islam - IAIN Lhokseumawe sukses melakukan sosialisasi ekonomi syariah kepada siswa aliyah tingkat akhir di Dayah Terpadu AlMuslimun, Kabupaten Aceh Utara. Siswa sangat bersemangat untuk sama-sama mengembangkan ekonomi syariah ke depannya. Siswa juga berharap dapat menjadi bagian langsung dalam pengembangan ekonomi syariah ke depannya.

Tim menyarankan kepada pihak Dayah Terpadu Al-Muslimun agar memasukkan pelajaran ekonomi syariah kepada siswa didik, guna memberikan pengetahuan dasar dan meningkatkan tingkat literasi kepada siswa. Jika tingkat literasi semakin meningkat, maka pengembangan ekonomi syariah ke depannya di tangan Muslim milenial semakin mudah. 


\section{UCAPAN TERIMA KASIH}

Tim sosialisasi Fakultas Ekonomi dan Bisnis Islam - IAIN Lhokseumawe mengucapkan terima kasih kepada unsur pimpinan FEBI - IAIN Lhokseumawe yang telah memberikan kesempatan kepada tim untuk melaksanakan sosialisasi kepada siswa aliyah di Dayah Terpadu AlMuslimun. Tim juga mengucapkan terima kasih kepada Pimpinan Dayah Terpadu Al-Muslimun, H. Arief Rahmatillah, Lc.,MA. yang telah menerima tim, memberikan dukungan dan memfasilitasi terselenggaranya acara sehingga dapat berjalan dengan sukses.

\section{DAFTAR PUSTAKA}

Amalia, E. (2008). Keadilan Distributif dalam Ekonomi Islam: Penguatan Peran LKM dan UKM di Indoensia. Jakarta: Rajagrafindo.

Amalia, E. (2010). Model Peta Potensi SDM Ekonomi Islam pada PTAI dan PTU Analisi Kurikulum: Pembelajaran dan Hubungannya dengan Kebutuhan SDM pada Industri Keuangan Syariah. Yogyakarta: IPIEF, Fakultas Ekonomi UMY.

Antara. (2021). Kelompok Milenial Dinilai Jadi Pasar Masa Depan Ekonomi Syariah. Retrieved April 7, 2021, from https://www.antaranews.com/berita/2082694/kelompok-milenialdinilai-jadi-pasar-masa-depan-ekonomi-syariah

Badan Pusat Statistik. (2020). Jumlah Penduduk Indonesia. Retrieved Maret 12, 2021, from www.bps.go.id

Hakim, R. (2017). Generasi Millennial Dan Ekonomi Syariah. Retrieved Maret 12, 2021, from file://C:/Users/ASUS/Downloads/1538-4116-1-PB.pdf

Hutagalung, M. A., Fitri, R., \& Ritonga, S. R. (2019). Generasi Muslim Milenial dan Wirausaha. Seminar Nasional Hasil Pengabdian Kepada Masyarakat 2019 (pp. 300-304). Pontianak: STMIK Pontianak.

Iswanto, A. (2018). Membaca Kecenderungan Pemikiran Islam Generasi Milenial Indonesia. Jurnal Multikultural \& Multireligius, 17(1), 177-184.

Laucereno, S. F. (2018). Generasi Milenial Harapan Baru Ekonomi Syariah RI. Retrieved Maret 12, 2021, from https://finance.detik.com/moneter/d-4240142/generasi-milenial-harapanbaru-ekonomi-syariah-ri

Masyarakat Ekonomi Syariah. (2019). Wakaf Uang Bagi Muslim Milenial. Retrieved April 7, 2021, from http://www.ekonomisyariah.org/7062/wakaf-uang-bagi-muslim-milenial/

Media Indonesia. (2020). Literasi Ekonomi dan Keuangan Syariah di Indonesia Masih Rendah. Retrieved April 7, 2021, from https://mediaindonesia.com/ekonomi/335724/literasiekonomi-dan-keuangan-syariah-di-indonesia-masih-rendah

Nurhidayat. (2020). Muslim Milenial dan Gerakan Ekonomi Islam Indonesia. MIZAN: Journal of Islamic Law, 4(1), 131-140, DOI: https://doi.org/10.32507/mizan.v4i1.638. 
Nursyamsiah, T. (2019). Milenial dan Gerakan Ekonomi Syariah. Retrieved April 7, 2021, from https://www.sharianews.com/posts/milenial-dan-gerakan-ekonomi-syariah

Rahmatillah, A. (2021, Pebruari). Jumlah Siswa di Dayah Al-Muslimun.

Republika. (2020). Milenial Kunci Pengembangan Ekonomi Syariah. Retrieved Maret 12, 2021, from https://www.republika.co.id/berita/qkpv7z423/milenial-kunci-pengembanganekonomi-syariah

Rosyid, M. A. (2021). Ekonomi Syariah Bisa Menjadi Pendorong Perekonomian. Retrieved April 4, 2021, from https://www.beritasatu.com/ekonomi/751387/komisaris-bsi-ekonomisyariah-bisa-menjadi-pendorong-perekonomian

Sayekti, I. M. (2021). Bank Syariah di Antara Milenial dan Bank 5.0. Retrieved Maret 12, 2021, from https://analisis.kontan.co.id/news/bank-syariah-di-antara-milenial-dan-bank-50

Tim Kementerian Pemberdayaan Perempuan dan Perlindungan Anak Dengan Pusat Statistik. (2018). Statistik Gender Tematik: Profil Generasi Milenial Indonesia. Jakarta: Kementerian Pemberdayaan Perempuan dan Perlindungan Anak. 